\title{
Transaction Costs as a Source of Consumer Stockpiling
}

\author{
${ }^{1}$ School of Business and Economics, Loughborough University, Loughborough, LE11 3TU, UK \\ ${ }^{2}$ Center for Economic Research, Shandong University, Jinan, China, E-mail: ruochen.li@sdu.edu.cn \\ ${ }^{3}$ School of Business and Economics, Loughborough University, Loughborough LE11 3TU, UK
}

\begin{abstract}
:
Consumers often stockpile goods to store for future consumption. The existing theoretical literature has focussed on a price-based explanation where stockpiling arises due to temporary price reductions. In contrast, this paper explores a transaction-cost-based explanation where consumers stockpile to avoid the need to incur future transaction costs. It shows how transaction costs lead to positive consumer stockpiling in an oligopoly equilibrium even when future prices are expected to fall. Relative to a no-stockpiling benchmark, such stockpiling lowers profits, but improves consumer and total welfare. Our results extend to the case of quantity discounts where stockpiling consumers pay relatively lower per-unit prices than non-stockpiling consumers, when purchasing multi-unit bundles.
\end{abstract}

Keywords: consumer stockpiling, differentiated markets, price discrimination, quantity discounts, transaction costs

JEL classification: L13, D43, D11, M31

DOI: $10.1515 /$ bejeap-2017-0316

\section{Introduction}

Consumers often stockpile goods to store for future consumption. Evidence of this phenomenon has been well documented for a host of retail products including cola, sugar, coffee, pasta, and laundry detergent, among many others (see Boizot, Robin, and Visser 2001; Pesendorfer 2002; Hendel and Nevo 2006a, for discussions and associated references). Stockpiling prompts intertemporal demand shifts from future to current periods. Recent research has stressed the theoretical and empirical importance of such demand shifts with applications across a wide range of economics and marketing, including merger analysis, the effects of indirect taxes, and sales promotions. ${ }^{1}$

The existing theoretical literature has focussed on a price-based explanation for stockpiling where consumers bring forward their purchases to take advantage of firms' temporary price reductions. ${ }^{2}$ However, past research has largely ignored an additional transaction-cost-based explanation where consumers stockpile to avoid future transaction costs. Consumers often need to incur transaction costs to make a purchase in many retail markets. Examples include the costs of visiting a store or ordering online and paying for a delivery. Furthermore, even if a consumer is already at a store or website, small transaction costs may still exist due to the effort of locating or collecting the product. By stockpiling, a consumer can minimise such transaction costs. ${ }^{3}$

As a simple illustration, consider a consumer visiting a liquor store. As consistent with the price-based explanation, the consumer may buy more beer than they want for immediate consumption due to the presence of a temporary special offer. However, in the absence of a special offer, the consumer may still stockpile for later consumption to avoid having to make another return trip even if they expect future prices to fall. In practice, consumers are often likely to stockpile due to both explanations - to take advantage of low prices and to minimise future transaction costs. Consequently, understanding this transaction-cost-based explanation together with its wider effects on price competition and market behaviour is important for future theoretical and empirical research on consumer stockpiling.

To fill this gap in the literature, this paper presents a model of stockpiling within a two-period duopoly. Products are differentiated within a random utility framework à la Perloff and Salop (1985). Each time a consumer makes a purchase from any given firm, the consumer incurs a positive transaction cost that is independent of the number of units bought. In each period, consumers wish to consume exactly one unit. Consumers can either buy one unit in each period or buy a second unit in period 1 to stockpile for consumption in period 
2. Firms are unable to commit to future prices; they set prices simultaneously each period. As most consistent with products that are purchased frequently, we initially assume that all agents have a discount factor close to one.

The paper first shows that any symmetric equilibrium involves a positive level of consumer stockpiling. This differs to the closest existing work on stockpiling in differentiated product markets by Guo and Villas-Boas (2007) which shows how there can be no stockpiling in equilibrium under the assumption of zero transaction costs (as detailed further below). Intuitively, the existence of positive transaction costs encourages consumers with relatively strong brand preferences to stockpile in order to avoid incurring further transaction costs in the future. In equilibrium, this prompts the firms to set period 1 prices that are strictly higher than period 2 prices. Thus, our transaction-cost-based explanation of stockpiling contrasts starkly to the price-based explanation, where positive equilibrium stockpiling only arises when prices are temporarily low.

The paper then analyses the impact of transaction-cost-based stockpiling on market welfare. In comparison to a no-stockpiling benchmark, there are three effects. First, period 2 prices are lower because the nonstockpiling consumers that remain in period 2 have relatively weak brand preferences, so competition becomes more intense. Second, period 1 prices are also lower because the existence of consumers who are willing to stockpile by purchasing an additional unit induces greater competition. Third, consumers who stockpile also economise on their transaction costs by only visiting the store once. These effects imply that equilibrium industry profits decrease, while consumer welfare and total welfare increase relative to the no-stockpiling benchmark.

As stockpiling helps the firms to sort consumers by the intensity of their relative brand preferences, these welfare results can also be understood in terms of price discrimination. When compared to the existing literature on oligopolistic price discrimination (e.g. Armstrong 2006), our welfare results are unusually crisp. For instance, Hendel and Nevo (2013) provide some ambiguous welfare findings when firms engage in intertemporal price discrimination between stockpiling and non-stockpiling consumers. In the context of price-based stockpiling, they show that stockpiling prompts periods of low prices, to attract the stockpiling consumers, followed by periods of high prices aimed at the non-stockpiling consumers; yet if stockpiling were prohibited, prices would be at an intermediate level. In contrast, in our transaction-cost-based model, stockpiling creates unambiguous welfare results by prompting lower prices in both periods and allowing stockpiling consumers to economise on transaction costs.

Next, we consider an extension where firms use quantity discounts whereby they set a single-unit price together with a special quantity-discounted price for a double-unit bundle in period 1 . The results verify that the symmetric equilibrium resembles that within the main model and still involves positive stockpiling. Moreover, it shows that the introduction of quantity discounts increases the equilibrium level of stockpiling. Intuitively, quantity discounts provide the firms with an extra pricing instrument which allows them to set relatively lower prices to stockpiling consumers and relatively higher prices to non-stockpiling consumers in period 1. Hence, stockpiling consumers pay lower average per-unit prices in period 1 than non-stockpiling consumers. This resonates with the observation that stockpiling consumers often buy at lower prices.

In terms of the existing literature, the closest paper to our own is Guo and Villas-Boas (2007). They consider stockpiling in a two-period Hotelling model with zero transaction costs and find the surprising result that there is no stockpiling in equilibrium. Intuitively, they show that consumers with relatively strong brand preferences are more likely to stockpile in period 1 . Hence, as more consumers stockpile, price competition in period 2 becomes more intense because only the consumers with relatively weak brand preferences remain. This effect is sufficient to deter firms from lowering prices in period 1 such that the equilibrium involves no consumer stockpiling. Our framework builds on their analysis (albeit within a different model of product differentiation) to demonstrate that the introduction of positive transaction costs ensures positive stockpiling in any symmetric equilibrium. In doing so, we become the first paper within the literature to analyse a transaction-cost-based explanation of stockpiling.

Another related paper is Hendel and Nevo (2013). As part of their wider structural investigation into intertemporal price discrimination, they offer a model of price-based stockpiling that can apply in a differentiated product market. Their model assumes an exogenous partition of consumers into storers and non-storers. In contrast, the partition between storers and non-storers in our model arises endogenously due to differences in the intensity of consumers' relative brand preferences. In further contrast, we also allow for the more realistic scenario where firms are unable to commit to a price path over time. However, similar to them, due to the challenges of fully demonstrating the existence of equilibria in dynamic models of stockpiling with differentiated products, we focus on fully characterising the unique local symmetric equilibrium. Any (global) symmetric equilibrium must necessarily have the properties of such a unique local symmetric equilibrium. For related reasons, Hendel and Nevo (2013) assume the concavity of their profit function.

More generally, our paper contributes to the wider research on equilibrium consumer stockpiling. To date, the associated literatures in economics and marketing have focussed on the price-based explanation of stockpiling. In particular, existing models largely consider homogeneous goods markets with an exogenous partition 
of stockpiling and non-stockpiling consumers. In equilibrium, some consumers stockpile in response to temporarily low prices (e.g. Salop and Stiglitz 1982; Sobel 1984; Pesendorfer 2002; Hong, McAfee, and Nayyar 2002; Bell, Iyer, and Padmanabhan 2002; Anton and Das Varma 2005; Hosken and Reiffen 2007; Gangwar, Kumar, and Rao 2013). Our analysis of the transaction-cost-based explanation contributes to this literature by providing a broader understanding of the determinants of stockpiling and the associated effects on price competition and market behaviour.

Finally, to model brand preferences, we use Perloff and Salop's (1985) random utility framework. This framework is being used increasingly in a variety of applications, such as bundling (Zhou 2017) and consumer search (Armstrong 2017). Alternatively, we could have modelled brand preferences using a Hotelling framework instead. However, our use of the random utility framework has the advantage of better highlighting the different effects of consumers' brand preferences and consumers' transaction costs (as further discussed below). Moreover, with suitable restrictions, it flexibly encompasses the Hotelling framework as a special case.

The paper proceeds as follows. Sections 2 and 3 develop an equilibrium model of transaction-cost-based stockpiling. Section 2 presents the model. Section 3 provides the equilibrium analysis. Section 4 presents the extension to consider quantity discounts. Section 5 covers a number of robustness issues including (i) heterogeneous stockpiling abilities, (ii) new consumers in period 2, (iii) infrequently purchased goods, and (iv) non-equilibrium price expectations. Section 6 concludes. All proofs are listed in the appendix.

\section{Model}

This section presents the model. Section 2.1 introduces the assumptions before Section 2.2 considers a benchmark case.

\subsection{Assumptions}

Consider a market where two firms, $i=\{A, B\}$, sell a single, horizontally differentiated, storable good with zero production costs over two periods, $t=\{1,2\}$. There is a unit mass of risk-neutral consumers with quasi-linear preferences who each want to consume one unit of the good per period. To model brand preferences, we use Perloff and Salop's (1985) random utility framework. In particular, having bought product $i$ in period $t$ at price, $p_{i t}$, let consumer $m$ 's net utility of consuming one unit of product $i$ equal $u_{i m}\left(p_{i t}\right)=\varepsilon_{i m}-p_{i t}$, where consumer $m^{\prime}$ s gross utility, $\varepsilon_{i m}$, is a consumer-firm specific match value. Such match values are independently distributed across firms and consumers, where $G\left(\varepsilon_{i m}\right)=G(\varepsilon) \forall i, m$. The match values also remain fixed throughout the game. For tractability, we assume that $G(\varepsilon)$ is a uniform distribution on $[a, b]$ with $a \geq 0$ and $\mu \equiv b-a>0$ such that $G(\varepsilon)=\frac{\varepsilon-a}{\mu}$ and $G^{\prime}(\varepsilon)=g(\varepsilon)=\frac{1}{\mu}$ for $\varepsilon \in[a, b]$.

Importantly, we assume that transactions are costly for consumers. Specifically, each time a consumer makes a purchase from any given firm, the consumer incurs a transaction cost, $k>0$, that is independent of the number of units bought. As detailed in the introduction, recall that such transaction costs may include the costs of visiting a firm, ordering a delivery or locating/collecting the product from within the firm's store or website.

Consumers' match values are best interpreted as deriving from their brand preferences rather than their geographical location. To further understand this, and how they relate to consumers' transaction costs, it is useful to consider the following scenario. Suppose consumer $m$ stockpiles by buying $z>1$ units of the good in a single transaction from firm $A$ at a price of $p$ per unit. Consumer $m$ then obtains $z\left(\varepsilon_{A m}-p\right)-\kappa$. In other words, consumer $m$ only incurs the transaction cost once, but obtains the same match value for each unit bought. Thus, geographical transport costs are most consistent with a form of transaction costs, whereas match values are best interpreted as deriving from brand preferences.

As standard, we let each consumer's outside option be sufficiently unattractive such that they always consume one unit of the good each period - although they need not buy each period due to the possibility of stockpiling. For simplicity, we also suppose that all agents have a discount factor close to one, as most appropriate for products that are purchased frequently (e.g. bottles of cola), and normalise any physical costs of stockpiling to zero. ${ }^{4}$ Finally, for our later analysis, it will prove useful to define consumer $m^{\prime}$ 's relative brand preference for firm $A$ over firm $B$ as $\psi_{m} \equiv \varepsilon_{A m}-\varepsilon_{B m} \in[-\mu, \mu]$. Thus, we interpret the parameter, $\mu$, as the degree of product differentiation.

The timing of the game is then as follows. In period 1 , each firm $i$ simultaneously chooses its period 1 price, $p_{i 1}$. Consumers then learn their match values for each firm and observe prices before making their purchase decisions. Each consumer must decide whether to buy either one unit for consumption in period 1 only, or an additional second unit to stockpile for consumption in period 2, and choose which firm(s) to buy from. In 
period 2, each firm then simultaneously chooses its period 2 price, $p_{i 2}$. Consumers observe these prices, and any remaining 'active' consumers that did not stockpile in period 1 then choose which firm to purchase from. We consider (pure-strategy) symmetric equilibria where the firms set period 1 price, $p_{1}^{*}$, and period 2 price, $p_{2}^{*}$. In particular, as noted in the introduction, we focus on characterising on the unique local symmetric equilibrium. Hence, we need only consider local deviations around a potential symmetric equilibrium.

\subsection{Benchmark Analysis}

Let us briefly examine a benchmark where stockpiling is prohibited. In this case, the two periods are identical. In any period $t$, a given consumer $m$ will purchase one unit from firm $i$ rather than firm $j$ if $u_{i m}\left(p_{i t}\right)-\kappa \geq$ $u_{j m}\left(p_{j t}\right)-\kappa$. Hence, consumer $m$ will prefer firm $i$ if her relative brand preference for firm $i, \varepsilon_{i m}-\varepsilon_{j m}$, exceeds the associated price difference, $p_{i t}-p_{j t}$. As such, consumer $m$ will buy one unit from firm $i$ with probability $\operatorname{Pr}\left(\varepsilon_{j m} \leq p_{i t}-p_{j t}+\varepsilon_{i m}\right)=G\left(p_{i t}-p_{j t}+\varepsilon_{i m}\right)$, and firm $i^{\prime}$ s demand in period $t$ equals

$$
Q_{i t}\left(p_{i t}, p_{j t}\right)=\int_{a}^{b} G\left(p_{i t}-p_{j t}+\varepsilon\right) g(\varepsilon) d \varepsilon=\frac{1}{2}+\frac{p_{j t}-p_{i t}}{\mu}
$$

After applying the usual first order condition for a symmetric equilibrium, $p_{i t}^{*}=-\left[Q_{i t}\left(p_{i t}^{*}, p_{i t}^{*}\right) / Q_{i t}^{\prime}\left(p_{i t}^{*}, p_{i t}^{*}\right)\right]$, one obtains the standard equilibrium price and quantity. Hence, in each period, each firm sets a benchmark price, $p^{B}=\frac{\mu}{2}$, sells to half of the consumers, $Q^{B}=\frac{1}{2}$, and earns (per-period) profits, $\pi^{B}=(\mu / 4)$. Note that the benchmark price and profits are increasing in the degree of product differentiation, $\mu$.

\section{Equilibrium Analysis}

We now consider the equilibrium of the full game by permitting stockpiling. To begin, Section 3.1 analyses consumers' decisions and demand, before Section 3.2 then endogenises firms' behaviour. Section 3.3 considers market welfare.

\subsection{Consumers' Decisions and Demand}

We first characterise some features of consumers' stockpiling decisions and demand in period 1 for a given set of period 1 prices $\left\{p_{A 1}, p_{B 1}\right\}$, and expected period 2 prices, $\left\{p_{A 2}^{e}, p_{B 2}^{e}\right\}$. Then, we consider period 2 demand given period 2 prices, $\left\{p_{A 2}, p_{B 2}\right\}$.

\subsubsection{Period 1}

Consider consumer $m$ 's options in period 1 given her match values $\left\{\varepsilon_{A m}, \varepsilon_{B m}\right\}$. She could: (i) stockpile by purchasing two units from some firm $i=\{A, B\}$ to gain

$$
U_{i m}^{S}=2 u_{i m}\left(p_{i 1}\right)-\kappa=2\left(\varepsilon_{i m}-p_{i 1}\right)-\kappa,
$$

(ii) stockpile by purchasing one unit from each firm to gain

$$
U_{m}^{S}=u_{A m}\left(p_{A 1}\right)+u_{B m}\left(p_{B 1}\right)-2 \kappa=\left(\varepsilon_{A m}-p_{A 1}\right)+\left(\varepsilon_{B m}-p_{B 1}\right)-2 \kappa,
$$

or (iii) not stockpile by purchasing one unit in each period to gain

$$
U_{m}^{N S}=\max \left\{u_{A m}\left(p_{A 1}\right), u_{B m}\left(p_{B 1}\right)\right\}+\max \left\{u_{A m}\left(p_{A 2}^{e}\right), u_{B m}\left(p_{B 2}^{e}\right)\right\}-2 \kappa .
$$

Then note the following. First, any consumer $m$ who stockpiles will always prefer to buy from a single firm under option (i) rather than from two firms under option (ii), because this avoids making two costly transactions, $\max \left\{U_{A m}^{S}, U_{B m}^{S}\right\}>U_{m}^{S} \forall m$. Hence, any consumer who buys their second unit from a firm in period 1 will also buy their first unit from the same firm. Second, consumer $m$ will therefore stockpile from $i$ if this yields a greater utility than: (a) stockpiling at $j$, such that

$$
\widehat{S}_{i m}=U_{i m}^{S}-U_{j m}^{S}=2\left(\varepsilon_{i m}-p_{i 1}\right)-2\left(\varepsilon_{j m}-p_{j 1}\right) \geq 0,
$$


and (b) not stockpiling at all, such that

$$
\tilde{S}_{i m}=U_{i m}^{S}-U_{m}^{N S} \geq 0 .
$$

One can state the following.

\section{Lemma 1.}

If consumer $m$ finds it optimal to stockpile from firm A (or firm B) in period 1, then so will any other consumer $l$ with relative brand preferences $\psi_{l} \equiv \varepsilon_{A l}-\varepsilon_{B l}>\psi_{m} \equiv \varepsilon_{A m}-\varepsilon_{B m}$ (or $\psi_{l}<\psi_{m}$ ).

As in Guo and Villas-Boas (2007), this implies a positive relationship between relative brand preferences and the propensity to stockpile from a given firm. Consequently, we can derive the set of consumers that stockpile from $A$ and $B$ by identifying two marginal consumers. In particular, by using Lemma 1 , one can define $\psi_{A}^{s}$ as the lowest value of $\psi_{m}=\varepsilon_{A m}-\varepsilon_{B m}$ at which consumer $m$ prefers to stockpile from firm $A$, and $\psi_{B}^{s}$ as the highest value of $\psi_{m}$ at which consumer $m$ prefers to stockpile from firm $B$. Consequently, as illustrated in Figure 1, those consumers with relative brand preferences, $\psi_{m} \in\left[\psi_{A}^{s}, \mu\right]$, constitute the set of consumers that stockpile from $A$, $X_{A}\left(\psi_{A}^{s}\right)$, and those consumers with relative brand preferences, $\psi_{m} \in\left[-\mu, \psi_{B}^{s}\right]$, constitute the set of consumers who stockpile from $B, X_{B}\left(\psi_{B}^{s}\right)$. Therefore, given there is a unit mass of consumers, $X_{i}\left(\psi_{i}^{s}\right)$ represents firm $i^{\prime} \mathrm{s}$ 'stockpiling demand' in period 1 . The values of $\psi_{A}^{s}$ and $\psi_{B}^{s}$ are later endogenised once we consider firms' pricing decisions.

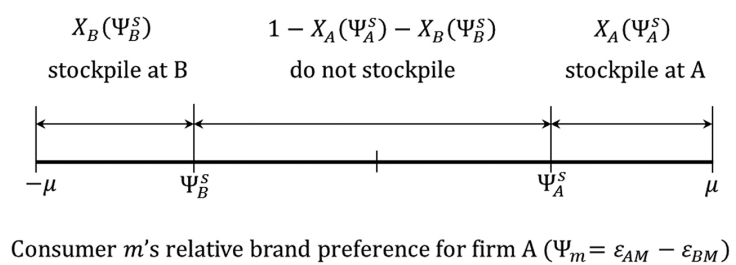

Figure 1: Consumers' stockpiling decisions.

We know that any consumer who buys two units in period 1 will do so from the same firm. Hence, firm $i$ 's set of stockpiling consumers, $X_{i}\left(\psi_{i}^{s}\right)$, is always a weak subset of the total number of consumers who purchase from firm $i$ in period 1. This leads to two possible cases. First, if $\psi_{A}^{s}=\psi_{B}^{s}$, then all consumers stockpile in period 1, $X_{A}\left(\psi_{A}^{s}\right)+X_{B}\left(\psi_{B}^{s}\right)=1$. Second, if $\psi_{A}^{s}>\psi_{B}^{s}$, then a positive measure of consumers $1-X_{A}\left(\psi_{A}^{s}\right)-X_{B}\left(\psi_{B}^{s}\right) \in(0,1]$ do not stockpile and only buy one unit in period 1 . Then noting that $Q_{i 1}\left(p_{i 1}, p_{j 1}\right)$, from Section 2.2, represents firm $i$ 's 'consumption' demand in period 1 (i.e. the units purchased for immediate consumption), we can then state:

\section{Lemma 2.}

Firm i's total demand in period 1 is defined as $\widehat{Q}_{i 1}()=.Q_{i 1}\left(p_{i 1}, p_{j 1}\right)+X_{i}\left(\psi_{i}^{s}\right)$, where:

$$
\hat{Q}_{i 1}(.)= \begin{cases}1+\frac{2}{\mu}\left(p_{j 1}-p_{i 1}\right) \equiv 2 Q_{i 1}\left(p_{i 1}, p_{j 1}\right) & \text { if } \psi_{A}^{s}=\psi_{B}^{s} \\ \frac{1}{2}+\frac{p_{j 1}-p_{i 1}}{\mu}+X_{i}\left(\psi_{i}^{s}\right)<2 Q_{i 1}\left(p_{i 1}, p_{j 1}\right) & \text { if } \psi_{A}^{s}>\psi_{B}^{s}\end{cases}
$$

If $\psi_{A}^{s}=\psi_{B}^{s}$, all consumers stockpile. Hence, firm $i^{\prime}$ s stockpiling demand is equal to its period 1 consumption demand, $X_{i}()=.Q_{i 1}($.$) , and so firm i$ 's total period 1 demand equals $\widehat{Q}_{i 1}()=.2 Q_{i 1}($.$) , where Q_{i 1}\left(p_{i 1}, p_{j 1}\right)$ coincides with the demand in the benchmark, eq. (1). If, instead, $\psi_{A}^{s}>\psi_{B}^{s}$, then only some consumers stockpile. Here, firm $i$ 's total period 1 demand equals $\widehat{Q}_{i 1}()=.Q_{i 1}\left(p_{i 1}, p_{j 1}\right)+X_{i}\left(\psi_{i}^{s}\right)$ because a total of $Q_{i 1}\left(p_{i 1}, p_{j 1}\right)$ consumers buy from firm $i$, of which $Q_{i 1}\left(p_{i 1}, p_{j 1}\right)-X_{i}\left(\psi_{i}^{s}\right)$ buy one unit and $X_{i}\left(\psi_{i}^{s}\right)$ buy two units.

\subsubsection{Period 2}

For period 2 demand, one can then state:

\section{Lemma 3}

Around any potential symmetric equilibrium, firm i's total demand in period 2 is defined as $\widehat{Q}_{i 2}()=.Q_{i 2}\left(p_{i 2}, p_{j 2}\right)-$ $X_{i}\left(\psi_{i}^{s}\right)$, where:

$$
\hat{Q}_{i 2}(.)= \begin{cases}0 & \text { if } \psi_{A}^{s}=\psi_{B}^{s} \\ \frac{1}{2}+\frac{p_{j 2}-p_{i 2}}{\mu}-X_{i}\left(\psi_{i}^{s}\right)>0 & \text { if } \psi_{A}^{s}>\psi_{B}^{s}\end{cases}
$$


If $\psi_{A}^{s}=\psi_{B}^{s}$, all consumers have stockpiled and so period 2 is inactive. However, if $\psi_{A}^{s}>\psi_{B}^{s}$, then consumers with $\psi_{m} \in\left(\psi_{B}^{S}, \psi_{A}^{s}\right)$ did not stockpile and so remain active. As in the benchmark, any such consumer will then buy one unit from firm $i$ rather than $j$ if $u_{i m}\left(p_{i 2}\right)-\kappa \geq u_{j m}\left(p_{j 2}\right)-\kappa$. It then follows that firm $i^{\prime}$ s total period 2 demand equals $Q_{i 2}\left(p_{i 2}, p_{j 2}\right)$, from eq. (1), minus those consumers that stockpiled from firm $i$ in period $1, X_{i}\left(\psi_{i}^{s}\right)$, from eq. (8).

\subsection{Firms' Decisions}

Given consumer demand, we now analyse the firms' equilibrium pricing decisions. First, we derive period 2 equilibrium prices for given levels of stockpiling. Second, we derive the equilibrium levels of stockpiling demand for given period 1 prices and expected period 2 prices, where consumers' expectations of period 2 prices are consistent with equilibrium. Third, given the equilibrium levels of stockpiling demand, we then solve for period 1 equilibrium prices.

\subsubsection{Period 2}

Period 2 is active only if $\psi_{A}^{s}>\psi_{B}^{s}$ such that $X_{A}\left(\psi_{A}^{s}\right)+X_{B}\left(\psi_{B}^{s}\right)<1$. If so, we can state:

\section{Lemma 4.} has

Suppose $\psi_{A}^{s}>\psi_{B}^{s}$. Then, provided $3-4 X_{i}\left(\psi_{i}^{s}\right)-2 X_{j}\left(\psi_{j}^{s}\right)>0 \forall i, j \neq i \in\{A, B\}$, the unique period 2 equilibrium

$$
\begin{array}{r}
p_{i 2}^{*}\left(X_{i}\left(\psi_{i}^{s}\right), X_{j}\left(\psi_{j}^{s}\right)\right)=\frac{\mu}{6}\left[3-4 X_{i}\left(\psi_{i}^{s}\right)-2 X_{j}\left(\psi_{j}^{s}\right)\right]>0 \\
\text { and } \widehat{Q}_{i 2}^{*}(.)=Q_{i 2}\left(p_{i 2}^{*}(.), p_{j 2}^{*}(.)\right)-X_{i}\left(\psi_{i}^{s}\right)=\frac{1}{6}\left[3-4 X_{i}\left(\psi_{i}^{s}\right)-2 X_{j}\left(\psi_{j}^{s}\right)\right]>0 .
\end{array}
$$

To characterise the properties of a potential symmetric equilibrium, we need only consider local deviations. Hence, provided that the firms' period 1 prices are sufficiently close such that their levels of stockpiling are not too dissimilar, with $3-4 X_{A}\left(\psi_{A}^{s}\right)-2 X_{B}\left(\psi_{B}^{s}\right)>0$ and $3-4 X_{B}\left(\psi_{B}^{s}\right)-2 X_{A}\left(\psi_{A}^{s}\right)>0$, Lemma 3 confirms that both firms will have positive period 2 equilibrium prices and demand. Moreover, as in Guo and Villas-Boas (2007), it suggests that (i) period 2 prices are weakly lower than in the benchmark due to the potential absence of the stockpiling consumers who have relatively strong brand preferences, and (ii) the firm with the largest level of stockpiling sets a lower period 2 price because it has proportionately less consumers with stronger brand preferences.

\subsubsection{Period 1}

We now derive the equilibrium levels of stockpiling demand for given period 1 prices and expected period 2 prices. Following this, we solve for the equilibrium prices in period 1.

\section{Equilibrium Stockpiling Demand}

In equilibrium, consumers' expectations of period 2 prices must be correct, $p_{i 2}^{e}=p_{i 2}^{*}\left(X_{i}(),. X_{j}().\right)$, for $i, j \neq i$ $\in\{A, B\}$. Hence, we now denote firm $i$ 's equilibrium level of stockpiling demand for given period 1 prices and period 2 equilibrium prices as $X_{i}^{*}\left(p_{i 1}, p_{j 1}, p_{i 2}^{*}(),. p_{j 2}^{*}().\right)$.

\section{Proposition 1.}

Around any symmetric equilibrium, the unique levels of equilibrium stockpiling demand for given period 1 prices, $\mathbf{X}=\left\{X_{i}^{*}(),. X_{j}^{*}().\right\}$, equal:

$$
\mathbf{X}= \begin{cases}\{0,0\} & \text { if } p_{i 1}>\frac{\mu}{2}+\kappa, p_{j 1}>\frac{\mu}{2}+\kappa \\ \left\{\frac{1}{2}-\left(\frac{2 p_{i 1}-p_{j 1}-\kappa}{\mu}\right), \frac{1}{2}-\left(\frac{2 p_{j 1}-p_{i 1}-\kappa}{\mu}\right)\right\} & \text { if } p_{i 1} \in\left(\frac{\kappa+p_{j 1}}{2}, \frac{\frac{\mu}{2}+\kappa+p_{j 1}}{2}\right], p_{j 1} \in\left(\frac{\kappa+p_{i 1}}{2}, \frac{\frac{\mu}{2}+\kappa+p_{i 1}}{2}\right] \\ \left\{\frac{1}{2}, \frac{1}{2}\right\} & \text { if } p_{i 1} \leq \kappa, p_{j 1} \leq \kappa\end{cases}
$$


When making their decision of whether or not to stockpile, the proof verifies that an indifferent consumer at $\psi_{i}^{S}$ optimally compares (i) the cost of stockpiling in period 1 by buying a second unit from firm $i, p_{i 1}$, versus (ii) the cost of returning to buy a second unit in period 2 from firm $i$, rather than $j, p_{i 2}^{*}\left(X_{i}(),. X_{j}().\right)+\kappa$. Hence, if both firms' period 1 prices are sufficiently high, then no consumer finds it optimal to stockpile as $p_{i 1}>p_{i 2}^{*}(0,0)+\kappa \equiv(\mu / 2)+\kappa$ for $i=\{A, B\}$. Similarly, if both firms' period 1 prices are sufficiently low, then all consumers find it optimal to stockpile as $p_{i 1} \leq p_{i 2}^{*}\left(\frac{1}{2}, \frac{1}{2}\right)+\kappa \equiv \kappa$ for $i=\{A, B\}$. This leaves the remaining case where both firms' period 1 prices are relatively moderate. Here, as in the middle line of eq. (10), there exists a unique level of equilibrium stockpiling, such that $p_{i 1}=p_{i 2}^{*}\left(X_{i}(),. X_{j}().\right)+\kappa$ for each firm. If firm $i^{\prime}$ s period 1 price was below (above) this level for given levels of $X_{i}$ and $X_{j}$, more (fewer) consumers would find it optimal to stockpile at the firm, which in turn would lower (raise) the firm's period 2 equilibrium price until this condition is satisfied. ${ }^{5}$

\section{Equilibrium Prices and Stockpiling}

We now complete the equilibrium by characterising period 1 prices. Firm $i$ 's associated profit function can be expressed as follows

$$
\pi_{i}(.)=p_{i 1}\left[Q_{i 1}\left(p_{i 1}, p_{j 1}\right)+X_{i}^{*}(.)\right]+p_{i 2}^{*}(.)\left[Q_{i 2}\left(p_{i 2}^{*}(.), p_{j 2}^{*}(.)\right)-X_{i}^{*}(.)\right]
$$

where firm $i$ receives period 1 total demand $\widehat{Q}_{i 1}()=.Q_{i 1}\left(p_{i 1}, p_{j 1}\right)+X_{i}^{*}$ (.) from eqs. (7) and (10), and (if active) sets a period 2 equilibrium price $p_{i 2}^{*}($.$) , in eq. (9), and receives a period 2$ equilibrium total demand $\widehat{Q}_{i 2}^{*}()=.Q_{i 2}\left(p_{i 2}^{*}(),. p_{j 2}^{*}().\right)-X_{i}^{*}$ (.) from eq. (8). To begin, we can then note the following important result.

\section{Proposition 2.} demand.

In any symmetric equilibrium with non-zero transaction costs, $\kappa>0$, each firm receives a positive level of stockpiling

Guo and Villas-Boas (2007) showed that when transaction costs are zero, there can be no stockpiling in equilibrium. In contrast, Proposition 2 shows that when transaction costs are strictly positive, stockpiling always occurs in any symmetric equilibrium. The intuition of this result is as follows. If there were no stockpiling in our model, we know from the benchmark that prices would be equal across periods, $p_{1}=p_{2}=p^{B}=\frac{\mu}{2}$. However, given transaction costs are positive, consumers would then optimally wish to stockpile to avoid incurring a second period transaction cost as then $p^{B}<p^{B}+\kappa$. Therefore, any symmetric equilibrium with $\kappa>0$ must instead involve a positive level of stockpiling for each firm, $X^{*}>0$. Hence, in any such symmetric equilibrium, each firm will have levels of total demand in period 1 and 2 equal to $\widehat{Q}_{1}^{*}=\frac{1}{2}+X^{*}$ and $\widehat{Q}_{2}^{*}=\frac{1}{2}-X^{*}$ respectively. In more detail, after solving for the equilibrium, we can now state the following:

\section{Proposition 3.}

In any symmetric equilibrium:

i) when transaction costs are low, $\kappa \in\left(0, \frac{\mu}{3}\right)$, each firm's unique level of stockpiling demand is $X^{*}=\frac{3 \kappa}{2 \mu} \in$ $\left(0, \frac{1}{2}\right)$, where $p_{1}^{*}=\frac{\mu-\kappa}{2} \in\left(\kappa, p^{B}\right), p_{2}^{*}=\frac{\mu-3 \kappa}{2} \in\left(0, p^{B}\right), \widehat{Q}_{1}^{*}=\frac{1}{2}+\frac{3 \kappa}{2 \mu} \in\left(\frac{1}{2}, 1\right)$ and $\widehat{Q}_{2}^{*}=\frac{1}{2}-\frac{3 \kappa}{2 \mu} \in\left(0, \frac{1}{2}\right)$.

ii) when transaction costs are high, $\kappa \geq \frac{\mu}{3}$, each firm's unique level of stockpiling demand is $X^{*}=\frac{1}{2}$, where $p_{1}^{*}=$ $\min \left\{\kappa, \frac{\mu}{2}\right\} \in\left(0, p^{B}\right], \widehat{Q}_{1}^{*}=1$ and $\widehat{Q}_{2}^{*}=0$.

When $\kappa \in\left(0, \frac{\mu}{3}\right)$, transaction costs are low relative to the degree of product differentiation, $\mu$, such that $p_{1}^{*}>\kappa$ in equilibrium. It then follows from Proposition 1 that $p_{1}^{*}=p_{2}^{*}+\kappa$ must hold, and that this price relationship uniquely determines an interior solution where each firm has a positive equilibrium level of stockpiling demand, $X^{*} \in\left(0, \frac{1}{2}\right)$. Alternatively, when $\kappa \geq \frac{\mu}{3}$, transaction costs are high relative to the degree of product differentiation, such that $p_{1}^{*} \leq \kappa$ in equilibrium. From Proposition 1 , this implies a corner solution where all consumers optimally stockpile, $X^{*}=\frac{1}{2}$.

In either the interior or corner solution, Proposition 3 shows that positive stockpiling arises in equilibrium even though the period 1 price is higher than the price in period $2, p_{1}^{*}>p_{2}^{*}$. This pricing pattern over time is due to the fact that consumers are willing to pay a higher price in period 1 to avoid a second transaction cost in period 2. This gives incentives to the firms to price higher in period 1 relative to period 2 . Thus, our transactioncost-based explanation of stockpiling contrasts starkly to the price-based explanation of stockpiling, where stockpiling only arises when prices are temporarily low. While our main model has been deliberately simplified to show this feature, our quantity discounts extension in Section 4 demonstrates how stockpiling consumers can purchase at lower period 1 prices than non-stockpiling consumers. 


\section{Comparative Statics}

Propositions 2 and 3 demonstrated how positive transactions costs lead to positive levels of equilibrium stockpiling. We now investigate how small changes in the level of transaction costs affect stockpiling. When transaction costs are high, $\kappa \geq \frac{\mu}{3}$, all consumers stockpile and so the equilibrium level of stockpiling demand, $X^{*}=\frac{1}{2}$, is insensitive to small changes in transaction costs. However, when transaction costs are low, we now demonstrate that the level of stockpiling is monotonically increasing in the level of transactions costs.

\section{Corollary 1.}

For any given $\kappa \in\left(0, \frac{\mu}{3}\right)$, the level of stockpiling demand in any symmetric equilibrium is strictly increasing in the level of transaction cost, $\frac{\partial X^{*}}{\partial \kappa}=\frac{3}{2 \mu}>0$.

To understand the intuition, first hold prices at their initial equilibrium levels with $p_{1}^{*}=p_{2}^{*}+\kappa$. An increase in $\kappa$ then raises the cost of future transactions and so encourages greater stockpiling. This then leads to two inter-related effects on prices. First, there is a reduction in period 1 prices because the increased proportion of consumers wanting to stockpile gives the firms an increased incentive to compete. Second, there is also a reduction in period 2 prices because more consumers stockpile and the remaining consumers in period 2 have relatively weaker brand preferences. As a result, in equilibrium, stockpiling increases and the prices in both periods find a new lower equilibrium level where $p_{1}^{*}=p_{2}^{*}+\kappa$ is restored.

\subsection{Welfare}

We now consider the welfare effects of stockpiling by comparing the equilibrium with the no-stockpiling benchmark in Section 2.2.

\section{Corollary 2.}

For any $\kappa>0$, compared to the no-stockpiling benchmark, any symmetric equilibrium with positive stockpiling has strictly higher consumer welfare and total welfare, and (weakly) lower industry profits.

First note that the equilibrium period 1 and 2 prices, $p_{1}^{*}$ and $p_{2}^{*}$, are lower than the no-stockpiling benchmark price, $p^{B}=\frac{\mu}{2}$. The logic for this builds on the explanation of Corollary 1 . The equilibrium period 1 price is lower than the no-stockpiling benchmark, because the presence of consumers who are able to stockpile by purchasing an additional unit induces greater competitive incentives. The equilibrium period 2 price is also lower than in the no-stockpiling benchmark, $p_{2}^{*}<p^{B}$, because the consumers who do not stockpile and remain active in period 2 are those consumers with relatively weak brand preferences, so competition becomes more intense. This, together with market coverage, implies that industry profits are less than the no-stockpiling benchmark.

Now consider consumer welfare, which is defined as consumer surplus minus any transaction costs incurred. In the no-stockpiling benchmark, all consumers incur a transaction cost of $\kappa>0$ in each period. In contrast, in any symmetric equilibrium with positive stockpiling, there is always a fraction of stockpiling consumers who do not incur the transaction cost in period 2. Therefore, given this and the lower prices in the presence of stockpiling, consumer welfare is strictly higher than in the no-stockpiling benchmark.

Finally, consider total welfare, which is defined as the the sum of consumer welfare and industry profits. Given market coverage, any decrease in industry profits is simply transferred into higher consumer surplus. Consequently, the effect on total welfare is determined solely by the effect on the transaction costs incurred. Thus, since more consumers avoid a transaction cost in period 2 under stockpiling, total welfare is higher than in the no-stockpiling benchmark. ${ }^{6}$

These welfare results can also be understood in terms of price discrimination. More specifically, in the interior solution, consumers' endogenous stockpiling decisions reveal their relative brand preferences in a way that allows the firms to price discriminate: consumers with relatively strong brand preferences stockpile and only pay the period 1 price, while those with weaker brand preferences do not stockpile and pay both the period 1 and period 2 prices. Despite this opportunity to price discriminate, our results show that equilibrium profits decrease due to the lower prices in both periods.

This result and the other findings of Corollary 2 are unusually crisp relative to the existing literature on oligopolistic price discrimination where welfare effects are typically complex and difficult to derive (e.g. Armstrong 2006). For instance, Hendel and Nevo (2013) provide some ambiguous welfare findings when firms engage in intertemporal price discrimination between stockpiling and non-stockpiling consumers. In the context of price-based stockpiling, they show that stockpiling prompts periods of low prices, to attract the stockpiling consumers, followed by periods of high prices aimed at non-stockpiling consumers; yet if stockpiling were prohibited, prices would be at an intermediate level. In contrast, in our transaction-cost-based model, stockpiling 
creates unambiguous welfare results when firms use positive stockpiling to discriminate between consumers with different brand preferences. In particular, stockpiling prompts lower prices in both periods and allows stockpiling consumers to economise on transaction costs.

\section{Extension-Quantity Discounts}

In the main model, we assumed that stockpiling consumers paid the same price for their first and second units in period 1. However, in practice, this may not be true as firms sometimes use special offers in the form of quantity discounts. For example, a firm may set a regular unit price of $\$ 1$ but then offer a special deal where a consumer can buy a two-unit bundle for $\$ 1.70$. Within our context, this translates to firm $i$ setting a single-unit price of $p_{i 1}$ to (non-stockpiling) consumers who only buy one unit in period 1, but a special quantity-discounted bundle price, $D_{i 1}$, for (stockpiling) consumers who buy two units in period 1. We now demonstrate how our results remain qualitatively robust to the introduction of quantity discounts, and how their use can lead to higher levels of equilibrium stockpiling.

Suppose both firms use quantity-discounted prices in the way described above. We necessarily assume $D_{i 1} \leq 2 p_{i 1}$ otherwise quantity discounts are redundant and we return to the scenario covered in the main model. Given this, if consumer $m$ stockpiles from firm $i$, she gains:

$$
U_{i m}^{D}=2 \varepsilon_{i m}-D_{i 1}-\kappa .
$$

This is similar to eq. (2) in the main model, except that, instead of paying for two single-units, $2 p_{i 1}$, the consumer pays the quantity-discounted price, $D_{i 1}$. Alternatively, if consumer $m$ does not stockpile then she still gains $U_{m}^{N S}$ in eq. (4) because the single unit prices, $p_{A 1}$ and $p_{B 1}$, remain relevant and unchanged from the main model.

With this in hand, one can then begin to find the equilibrium by performing similar steps to those in the main model. First, note that Lemmas 1-4 still apply directly for a given level of stockpiling because the structure of period 2 prices remains unchanged by the introduction of quantity discounts. To then derive stockpiling demand, $\mathbf{X}=\left\{X_{i}^{*}(),. X_{j}^{*}().\right\}$, one must again consider the relevant decision for a stockpiling consumer at the margin. As before, this involves comparing (a) the cost of stockpiling in period 1 by buying a second unit from the consumer's preferred firm, say firm $i$, versus (b) the cost of returning to buy a second unit in period 2 from firm $i$. In the main model, the cost of option (a) was simply $p_{i 1}$, and the cost of option (b) was $p_{i 2}^{*}\left(X_{i}(),. X_{j}().\right)+\kappa$. However, now under quantity discounts, the cost of option a) is equal to the effective price of buying a second unit, $D_{i 1}-p_{i 1}$, whereas the cost of option $\mathrm{b}$ ) remains unchanged. Hence, such a consumer will now strictly prefer to stockpile if $D_{i 1}-p_{i 1}<p_{i 2}^{*}\left(X_{i}(),. X_{j}().\right)+\kappa$. Thus, a new version of stockpiling demand in Proposition 1 can be derived by simply replacing $p_{i 1}$ with the new effective cost of stockpiling a second unit, $D_{i 1}-p_{i 1}$, for both firm $i$ and firm $j$.

Quantity discounts also affect firm $i$ 's profit function, which is now expressed as follows:

$$
\pi_{i}(.)=p_{i 1}\left[Q_{i 1}\left(p_{i 1}, p_{j 1}\right)-X_{i}(.)\right]+D_{i 1} \cdot X_{i}^{*}(.)+p_{i 2}^{*}(.)\left[Q_{i 2}\left(p_{i 2}^{*}(.), p_{j 2}^{*}(.)\right)-X_{i}^{*}(.)\right] .
$$

This has three elements. First, firm $i$ sets its single-unit period 1 price, $p_{i 1}$, to non-stockpiling consumers who buy from firm $i$ in period $1, Q_{i 1}\left(p_{i 1}, p_{j 1}\right)-X_{i}^{*}($.$) . Second, firm i$ sets its quantity-discounted bundle price, $D_{i 1}$, to stockpiling consumers who buy from firm $i, X_{i}^{*}($.$) . Third, firm i$ sets its second period price, $p_{i 2}^{*}($.$) , to non-$ stockpilers who buy from firm $i$ in period $2, Q_{i 2}\left(p_{i 2}^{*}(),. p_{j 2}^{*}().\right)-X_{i}^{*}($.$) . Note eq. (13) reduces to the equivalent$ expression in the main model eq. (11) when no quantity discounts are applied, $D_{i 1}=2 p_{i 1}$. After denoting $D_{1}^{*}$ as the equilibrium bundle price, we can then state the following:

\section{Proposition 4.}

In any symmetric equilibrium with quantity discounts:

i) when transaction costs are low, $\kappa \in\left(0, \frac{\mu}{4}\right)$, each firm's unique level of stockpiling demand is $X^{*}=\frac{2 \kappa}{\mu} \in\left(0, \frac{1}{2}\right)$, where $p_{1}^{*}=p^{B}=\frac{\mu}{2}, D_{1}^{*}=\mu-\kappa \in\left(\frac{3 \mu}{4}, 2 p_{1}^{*}\right), p_{2}^{*}=\frac{\mu}{2}-2 \kappa \in\left(0, p_{1}^{*}\right), \widehat{Q}_{1}^{*}=\frac{1}{2}+\frac{2 \kappa}{\mu} \in\left(\frac{1}{2}, 1\right)$ and $\widehat{Q}_{2}^{*}=\frac{1}{2}-\frac{2 \kappa}{\mu} \in\left(0, \frac{1}{2}\right)$.

ii) when transaction costs are high, $\kappa \geq \frac{\mu}{4}$, each firm's unique level of stockpiling demand is $X^{*}=\frac{1}{2}$, where $D_{1}^{*} \equiv$ $2 p_{1}^{*}=\min \{2 \kappa, \mu\} \in\left(0,2 p^{B}\right], \widehat{Q}_{1}^{*}=1$ and $\widehat{Q}_{2}^{*}=0$.

Hence, for all $x>0$, the introduction of quantity discounts leads to a weakly higher level of equilibrium stockpiling.

Proposition 4 verifies that the symmetric equilibrium still involves positive stockpiling, and qualitatively resembles that in the main model. Moreover, when compared to the main model, it shows that the introduction of quantity discounts weakly increases the equilibrium level of consumer stockpiling. Intuitively, this can be 
understood as follows. Under quantity discounts, a firm has an extra pricing instrument because it can now use different prices for consumers purchasing one or two units in period 1. This leads to two implications. First, when compared to the main model, this allows the firm to reduce the effective price for a second unit, $D_{1}^{*}-p_{1}^{*}$, without damaging its period 1 revenues from non-stockpiling consumers. Hence, the firms face an increased incentive to compete for stockpiling consumers. This results in a lower effective price for the second unit which increases the equilibrium level of stockpiling demand, $X^{*}$. In turn, the increase in stockpiling activity also reduces the subsequent equilibrium price in period $2, p_{2}^{*}$. Second, quantity discounts also allow the firms to increase their period 1 prices to non-stockpilers, $p_{1}^{*}$. By having an extra pricing instrument, the incentives to price to non-stockpiling consumers can be separated from the incentives to compete for stockpiling consumers. Relative to the main model, this allows the firms to charge non-stockpiling consumers a higher period 1 price equal to the benchmark price, $p^{B}$.

Finally, we end this section, by reviewing the results in light of the alternative price-based explanation for stockpiling. Consider the interior equilibrium. Here, unlike the main model, stockpiling consumers pay an average per-unit price in period 1 that is strictly lower than that paid by non-stockpiling consumers, $\frac{D_{1}^{*}}{2}<p_{1}^{*}$. As in the example of a single unit price of $\$ 1$ and a bundle price of $\$ 1.70$, this resonates with the observation that stockpiling consumers often pay relatively lower per-unit prices than non-stockpiling consumers when taking advantage of special offers. However, like the main model, our quantity discounts equilibrium still implies that stockpiling consumers pay a higher (effective) price on their second unit than non-stockpiling consumers as $D_{1}^{*}-p_{1}^{*}>p_{2}^{*}$.

\section{Robustness}

In this section, we further explore the robustness of our main results with regard to four factors: (i) heterogeneous stockpiling abilities, (ii) new consumers in period 2, (iii) infrequently purchased goods, and (iv) nonequilibrium price expectations.

\subsection{Heterogeneous Stockpiling Abilities}

In the main model, we assumed that consumers' brand preferences are heterogeneous but they share a common ability to stockpile. Given consumers in the real world may differ in their ability to stockpile, we now show that our main result does not depend upon this assumption. More specifically, in addition to the unit mass of original consumers with a transaction $\operatorname{cost} \kappa>0$, now suppose that there is an extra mass $\alpha$ of consumers who are unable to stockpile but share the same match value distribution, $G(\varepsilon)$. Hence, as these new consumers are unable to stockpile, they will demand one unit of the good in both period 1 and period 2 regardless of the level of prices. ${ }^{7}$ Proposition 5 shows that stockpiling will still be a feature of any symmetric equilibrium.

\section{Proposition 5.}

Suppose only a subset of consumers are able to stockpile with $\kappa>0$, then in any symmetric equilibrium each firm receives a positive level of stockpiling demand.

The intuition is closely related to that of Proposition 2. In particular, in the event of no stockpiling, we know from Section 2.2 that the firms would set prices at the benchmark level in both periods, $p^{B}=\frac{\mu}{2}$. The reason is that the new consumers' match values are drawn from the same distribution $G(\varepsilon)$, and so the firms' pricing incentives do not change. However, if prices are equal across periods, $p_{1}=p_{2}=p^{B}$, then that any consumer who can stockpile with $\kappa>0$ will do so to avoid incurring a second transaction cost as $p^{B}<p^{B}+\kappa$. Thus, positive stockpiling demand will be a feature of any symmetric equilibrium where a subset of consumers have positive transaction costs.

\subsection{New Consumers in Period 2}

Up until now, period 2 has only involved competition for non-stockpiling consumers. However, in reality, new consumers may also enter the market at this point. To further understand how the presence of such newcomers would affect the main result, consider the introduction of a mass $\alpha$ of new consumers in period 2 who were not active in the market in period 1. Like the original consumers, the consumers have unit demand with a match value distribution, $G(\varepsilon)$. Following similar arguments of the previous subsection, one can show that any symmetric equilibrium must still have a positive level of stockpiling demand. Intuitively, in the event of no 
stockpiling, firms would still set prices at the benchmark level in both periods, $p^{B}=\frac{\mu}{2}$. Hence, this cannot be an equilibrium, because the original consumers would then have an incentive to stockpile.

\subsection{Infrequently Purchased Goods}

In the main model, we assumed that all agents had a discount factor equal to one, as most appropriate for frequently purchased products. However, to show how our main result is robust for products that are purchased less frequently, now suppose that all agents discount the second period with a discount factor equal to $\delta<1$. After re-deriving the preliminary results, one must again consider the relevant decision for a stockpiling consumer at the margin, consumer $m$. This now involves the following comparison. On the one hand, consumer $m$ could stockpile a second unit in period 1 from their preferred firm, firm $i$. This would provide a discounted payoff of $\delta \varepsilon_{i m}-p_{i 1}$. On the other hand, consumer $m$ could return to buy a second unit in period 2 from firm $i$. This would provide a discounted payoff of $\delta\left(\varepsilon_{i m}-p_{i 2}-\kappa\right)$. Hence, the key interior equilibrium price condition where consumer $m$ is indifferent becomes $p_{1}^{*}=\delta\left(p_{2}^{*}+\kappa\right)$ instead of $p_{1}^{*}=p_{2}^{*}+\kappa$. One can then verify that positive stockpiling remains part of any symmetric equilibrium provided the agents are sufficiently patient with a discount factor that is close enough to one. Intuitively, in the event of no stockpiling, firms would still set prices at the benchmark level in both periods, $p^{B}=\frac{\mu}{2}$. However, this cannot be an equilibrium when the discount factor is sufficiently large such that $p^{B}<\delta\left(p^{B}+\kappa\right)$ because then consumers would prefer to stockpile.

\subsection{Non-Equilibrium Price Expectations}

In the main model, consumers have expectations of future prices that are correct in equilibrium. Alternatively, now consider a 'behavioural' setting where consumers naively expect prices to remain the same in the second period, such that $p_{i 2}^{e}=p_{i 1}$. In this case, consumers will always stockpile to avoid the transaction cost, since then $p_{i 1}<p_{i 2}^{e}+\kappa$ for all $\kappa>0$, such that $\mathbf{X}=\left\{\frac{1}{2}, \frac{1}{2}\right\}$. Hence, this situation will resemble the corner solution within the main model where the equilibrium price in period 1 is equal to the benchmark price, each consumer purchases two units, and period 2 is inactive.

\section{Conclusions}

Consumers often stockpile goods for future consumption. Such stockpiling prompts intertemporal demand shifts from future to current periods with important theoretical and empirical implications across a wide range of economics and marketing. The existing theoretical literature has focussed on a price-based explanation where consumers bring forward their purchases to take advantage of firms' temporary price reductions. In contrast, this paper has explored an under-researched transaction-cost-based explanation where consumers stockpile to avoid the need to incur future transaction costs. Our analysis should help future research by offering a broader understanding of the determinants of stockpiling and the associated effects on price competition and market behaviour.

Within an oligopoly equilibrium, our paper has showed how transaction costs lead to positive consumer stockpiling even when future prices are expected to fall. Such stockpiling helps the firms to sort consumers by the intensity of their relative brand preferences. Despite this, as a crisp example of the competitive effects of oligopolistic price discrimination, the paper has shown that stockpiling lowers industry profits, but improves consumer and total welfare. Finally, we have demonstrated how our results remain robust to the use of quantity discounts. This extra pricing instrument generates higher levels of equilibrium stockpiling and allows stockpiling consumers to pay lower average per-unit prices in period 1. This resonates with the observation that such consumers often buy at lower prices than non-stockpiling consumers.

\section{Acknowledgements:}

We are very thankful for comments from the editor (Hendrik Juerges), two anonymous referees, Tobias Wenzel, and from various conference and seminar audiences including EARIE (2017), Jornadas de Econom \'ra Industrial (2017), Nottingham University Business School and Loughborough University. Li acknowledges the support from "The Fundamental Research Funds of Shandong University (2019HW008)". 


\section{Appendix}

\section{Proof of Lemma 1.}

From eqs. (5) and (6), consumer $m$ will stockpile if (a) $\hat{S}_{i m}=U_{i m}^{S}-U_{j m}^{S} \geq 0$ and (b) $\tilde{S}_{i m}=U_{i m}^{S}-U_{m}^{N S} \geq 0$. Suppose condition (a) holds, with $U_{i m}^{S} \geq U_{j m}^{S}$ which implies $\left(\varepsilon_{i m}-p_{i 1}\right)-\left(\varepsilon_{j m}-p_{j 1}\right) \geq 0$. It then follows from eq. (4) that $U_{m}^{N S}=u_{i m}\left(p_{i 1}\right)+\max \left\{u_{A m}\left(p_{A 2}^{e}\right), u_{B m}\left(p_{B 2}^{e}\right)\right\}-2 \kappa$, such that condition (b) can be rewritten as $\tilde{S}_{i m}=\left(\varepsilon_{i m}-p_{i 1}\right)-\max \left\{\varepsilon_{i m}-p_{i 2}^{e}, \varepsilon_{j m}-p_{j 2}^{e}\right\}+\kappa \geq 0$. Therefore, $\hat{S}_{i m}$ (or $\left.\tilde{S}_{i m}\right)$ is then strictly (or weakly) increasing in consumer $m^{\prime}$ s relative brand preference for firm $i,\left(\varepsilon_{i m}-\varepsilon_{j m}\right) \in[-\mu, \mu]$.

\section{Proof of Lemma 2.}

If $\psi_{A}^{s}=\psi_{B}^{s}$, all consumers stockpile. Here, using eq. (2), any given consumer will buy two units from $i$ rather than $j$ in period 1 if $2\left(\varepsilon_{i}-p_{i 1}\right)-\kappa \geq 2\left(\varepsilon_{j}-p_{j 1}\right)-\kappa$. This comparison reduces down to that in the benchmark, $\varepsilon_{i}-p_{i 1} \geq \varepsilon_{j}-p_{j 1}$. Hence, firm i's total period 1 demand equals $\widehat{Q}_{i 1}()=.2 Q_{i 1}($.$) , where Q_{i 1}\left(p_{i 1}, p_{j 1}\right)$ coincides with the benchmark demand, eq. (1).

If, instead, $\psi_{A}^{s}>\psi_{B}^{s}$, some consumers only buy one unit in period 1 . As in the benchmark, such consumers will buy one unit from firm $i$ rather than $j$ in period 1 if $u_{i m}\left(p_{i 1}\right)-\kappa \geq u_{j m}\left(p_{j 1}\right)-\kappa$. Hence, as coinciding with the benchmark demand in eq. (1), a total of $Q_{i 1}\left(p_{i 1}, p_{j 1}\right)$ consumers buy from firm $i$ in period 1 . Of these, $Q_{i 1}\left(p_{i 1}, p_{j 1}\right)-X_{i}\left(\psi_{i}^{s}\right)$ consumers buy one unit and $X_{i}\left(\psi_{i}^{s}\right)$ consumers buy two units, such that total demand equals $\widehat{Q}_{i 1}()=.Q_{i 1}\left(p_{i 1}, p_{j 1}\right)+X_{i}\left(\psi_{i}^{s}\right)$.

\section{Proof of Lemma 3.}

If $\psi_{A}^{s}=\psi_{B}^{s}$, all consumers stockpile and so $\widehat{Q}_{i 2}()=$.0 . If instead, $\psi_{A}^{s}>\psi_{B}^{s}$, then consumers with $\psi_{m} \in$ $\left(\psi_{B}^{S}, \psi_{A}^{S}\right)$ did not stockpile and so remain active in period 2. As in the benchmark, any such consumer will then buy one unit from firm $i$ rather than $j$ in period 2 if $u_{i m}\left(p_{i 2}\right)-\kappa \geq u_{j m}\left(p_{j 2}\right)-\kappa$, and one can define $\psi_{2}$ as the value of $\psi_{m}=p_{A 2}-p_{B 2}$ at which such a consumer would be indifferent. Around any symmetric equilibrium, $\psi_{2} \in\left(\psi_{B}^{s}, \psi_{A}^{s}\right)$. Hence, there is a positive measure of consumers with $\psi_{m} \in\left(\psi_{B}^{S}, \psi_{2}\right)$ that strictly prefer to buy from firm $B$ and a positive measure of consumers with $\psi_{m} \in\left(\psi_{2}, \psi_{A}^{S}\right)$ that strictly prefer to buy from firm $A$. As in eq. (8), this implies that firm $i s$ total period 2 demand is equal to the benchmark demand, $Q_{i 2}\left(p_{i 2}, p_{j 2}\right)$ from eq. (1), minus those consumers that stockpiled from firm $i$ in period $1, X_{i}\left(\psi_{i}^{s}\right)$.

\section{Proof of Lemma 4.}

Suppose $\psi_{A}^{s}>\psi_{B}^{s}$. Then in any symmetric equilibrium, it must be the case that $\psi_{2} \in\left(\psi_{B}^{s}, \psi_{A}^{s}\right)$ such that both firms have positive demand. After defining firm $i^{\prime}$ s period 2 profit function as $\pi_{i 2}()=.p_{i 2} \widehat{Q}_{i 2}($.$) and$ substituting in eq. (8), one can derive firm $i$ 's period 2 best response for given stockpiling levels, $p_{i 2}\left(p_{j 2}\right)=$ $\frac{p_{j 2}}{2}+\frac{\mu}{2}\left(\frac{1}{2}-X_{i}\left(\psi_{i}^{S}\right)\right)$ for $i, j \neq i \in\{A, B\}$. After repeating for firm $j$ and solving simultaneously one obtains the unique period 2 equilibrium prices, $p_{i 2}^{*}()=.\frac{\mu}{6}\left[3-4 X_{i}\left(\psi_{i}^{s}\right)-2 X_{j}\left(\psi_{j}^{s}\right)\right]$. Substituting these back into eq. (8) gives $\widehat{Q}_{i 2}^{*}()=.\frac{1}{6}\left[3-4 X_{i}\left(\psi_{i}^{s}\right)-2 X_{j}\left(\psi_{j}^{s}\right)\right]$. All such prices and demands are positive if $4 X_{i}\left(\psi_{i}^{s}\right)+2 X_{j}\left(\psi_{j}^{s}\right)<3$ for all $i, j \neq i \in A, B$, which ensures $\psi_{2} \in\left(\psi_{B}^{s}, \psi_{A}^{s}\right)$ as claimed.

\section{Proof of Proposition 1.}

Having derived period 2 equilibrium prices, we first consider consumers' stockpiling decisions, before deriving the equilibrium levels of stockpiling demand as a function of period 1 prices, in eq. (10).

First, consider consumers' stockpiling decisions and initially suppose that each firm has positive period 2 demand with $\psi_{2} \in\left(\psi_{B}^{s}, \psi_{A}^{s}\right)$. This implies that a consumer at $\psi_{i}^{s}$ makes her stockpiling decision by comparing (i) the net marginal benefits of stockpiling from firm $i$, with (ii) the net marginal benefits of waiting to buy from firm $i$, rather than firm $j$, in period 2. From eq. (6), this implies $\tilde{S}_{i m}\left(\psi_{i}^{s}\right)=\left(\varepsilon_{i m}-p_{i 1}\right)-\left(\varepsilon_{i m}-p_{i 2}^{*}()-.\kappa\right)$. By construction, the consumer at $\psi_{i}^{s}$ is indifferent between stockpiling, such that $\tilde{S}_{i m}\left(\psi_{i}^{s}\right)=0$. Hence, this indifference requires $p_{i 1}=p_{i 2}^{*}\left(X_{i}(),. X_{j}().\right)+\kappa$.

We are now in a position to derive the equilibrium levels of stockpiling demand as a function of period 1 prices. First, consider the top line of eq. (10). Here, $p_{A 1}>p_{A 2}^{*}(0,0)+\kappa$ and $p_{B 1}>p_{B 2}^{*}(0,0)+\kappa$ such that no consumer finds it optimal to stockpile, $X_{A}^{*}()=.X_{B}^{*}()=$.0 . From eq. (9), $p_{i 2}^{*}(0,0)=\frac{\mu}{2}$ for both $i=\{A, B\}$, and so this case occurs when $p_{A 1}>\frac{\mu}{2}+\kappa$ and $p_{B 1}>\frac{\mu}{2}+\kappa$.

Second, consider the bottom line of eq. (10). Here, $p_{A 1} \leq p_{A 2}^{*}\left(\frac{1}{2}, \frac{1}{2}\right)+\kappa$ and $p_{B 1} \leq p_{B 2}^{*}\left(\frac{1}{2}, \frac{1}{2}\right)+\kappa$ such that all consumers find it optimal to stockpile, $X_{A}^{*}()=.X_{B}^{*}()=.\frac{1}{2}$. Period 2 prices are unspecified as period 2 is inactive. However, if the marginal consumer at $\psi_{A}^{s}=\psi_{B}^{s}=0$ were to deviate from stockpiling, we know from 
eq. (9) that she should rationally expect zero period 2 prices, $\lim _{X_{i} \rightarrow 0.5} p_{i 2}^{*}\left(X_{i}, \frac{1}{2}\right)=0$. Hence, this case occurs when $p_{A 1} \leq \kappa$ and $p_{B 1} \leq \kappa$.

Third, consider the middle line of eq. (10). Here, there exists a unique level of equilibrium stockpiling, $X_{i}^{*}(.) \in\left(0, \frac{1}{2}\right)$ and $X_{j}^{*}(.) \in\left(0, \frac{1}{2}\right)$, such that $p_{i 1}=p_{i 2}^{*}\left(X_{i}(),. X_{j}().\right)+\kappa$ holds for each firm. To find such $X_{i}^{*}($. and $X_{j}^{*}($.$) , one can insert p_{i 2}^{*}\left(X_{i}(),. X_{j}().\right)$ from eq. (9) to obtain

$$
X_{i}^{*}(.)=\frac{3}{4}-\frac{X_{j}^{*}(.)}{2}-\frac{3\left(p_{i 1}-\kappa\right)}{2 \mu} .
$$

After deriving a similar equation for $X_{j}^{*}$ (.) and solving simultaneously, one finds a unique level of $X_{i}^{*}()=$. $\frac{1}{2}-\left(\frac{2 p_{i 1}-p_{j 1}-\kappa}{\mu}\right)$ for $i, j \neq i \in\{A, B\}$. For $X_{i}^{*}(.) \in\left(0, \frac{1}{2}\right)$, we require $p_{i 1} \in\left(\frac{\kappa+p_{j 1}}{2}, \frac{\frac{\mu}{2}+\kappa+p_{j 1}}{2}\right]$ for each firm.

Finally, note that the levels of stockpiling and associated conditions in eq. (10) are continuous as (i) $\frac{1}{2}-$ $\left(\frac{2 p_{i 1}-p_{j 1}-\kappa}{\mu}\right)=\frac{1}{2}$ when $p_{i 1}=p_{j 1}=\kappa$, (ii) $\frac{1}{2}-\left(\frac{2 p_{i 1}-p_{j 1}-\kappa}{\mu}\right)=0$ when $p_{i 1}=p_{j 1}=\frac{\mu}{2}+\kappa$, (iii) $\frac{\kappa+p_{j 1}}{2}=\kappa$ when $p_{i 1}=\kappa$, and iv) $\frac{1}{2}\left[\frac{\mu}{2}+\kappa+p_{i 1}\right]=\frac{\mu}{2}+\kappa$ when $p_{i 1}=\frac{\mu}{2}+\kappa$.

\section{Proof of Proposition 2.}

From eq. (10), $X_{A}^{*}()=.X_{B}^{*}()=$.0 necessarily requires $p_{A 1}>\frac{\mu}{2}+\kappa$ and $p_{B 1}>\frac{\mu}{2}+\kappa$. However, we know from the benchmark analysis in Section 2.2 that $X_{A}^{*}()=.X_{B}^{*}()=0$ is consistent with $p_{1}=p_{2}=p^{B}=\frac{\mu}{2}$. This then leads to a contradiction as $p_{1}<\frac{\mu}{2}+\kappa$ for all $\kappa>0$.

\section{Proof of Proposition 3.}

First suppose that period 2 is active with $\psi_{A}^{s}>\psi_{B}^{s}$ such that $X_{A}^{*}()+.X_{B}^{*}()<$.1 . In any symmetric equilibrium each firm has positive period 2 demand with $\psi_{2} \in\left(\psi_{B}^{s}, \psi_{A}^{s}\right)$. Using eqs. (8) and (9), firm $i^{\prime}$ s profit function from eq. (11) can then be rewritten as:

$$
\pi_{i}(.)=p_{i 1}\left[Q_{i 1}\left(p_{i 1}, p_{j 1}\right)+X_{i}^{*}(.)\right]+\mu\left(\frac{3-4 X_{i}^{*}(.)-2 X_{j}^{*}(.)}{6}\right)^{2}
$$

where $Q_{i 1}()=.\frac{1}{2}+\frac{p_{j 1}-p_{i 1}}{\mu}$ from eq. (1), and where $X_{i}^{*}$ (.) and $X_{j}^{*}$ (.) are given in eq. (10). To maximise eq. (15) with respect to $p_{i 1}$ note that $\frac{\partial \pi_{i 1}}{\partial p_{i 1}}$ equals

$$
Q_{i 1}(.)+X_{i}^{*}(.)+p_{i 1}\left(\frac{\partial Q_{i 1}(.)}{\partial p_{i 1}}+\frac{\partial X_{i}^{*}(.)}{\partial p_{i 1}}\right)+\frac{\mu}{3}\left(3-4 X_{i}^{*}(.)-2 X_{j}^{*}(.)\right)\left(-\frac{2}{3} \frac{\partial X_{i}^{*}(.)}{\partial p_{i 1}}-\frac{1}{3} \frac{\partial X_{j}^{*}(.)}{\partial p_{i 1}}\right),
$$

where $\frac{\partial Q_{i 1}(.)}{\partial p_{i 1}}=-\frac{1}{\mu}, \frac{\partial X_{i}^{*}(.)}{\partial p_{i 1}}=-\frac{2}{\mu}$ and $\frac{\partial X_{j}^{*}(.)}{\partial p_{i 1}}=\frac{\partial X_{i}^{*}(.)}{\partial p_{j 1}}=\frac{1}{\mu}$. After expanding, enforcing symmetry with $p_{i 1}=$ $p_{j 1}=p_{1}^{*}$, and setting equal to zero, one obtains a unique value for $p_{1}^{*}=\frac{\mu-\kappa}{2}$. There are no profitable local deviations as the associated second-order condition ensures local concavity, $\frac{\partial^{2} \pi_{i}(.)}{\partial p_{i 1}^{2}}=-\frac{4}{\mu}<0$. Then substituting $p_{1}^{*}$ into eqs. (10), (9), (7) and (8) provides the unique values for $X^{*}, p_{2}^{*}, \widehat{Q}_{1}^{*}$ and $\widehat{Q}_{2}^{*}$ as claimed. For period 2 to be active as assumed, we require $X^{*}=\frac{3 \kappa}{2 \mu}<0.5$. This implies $\kappa<\mu / 3$, which further ensures that the equilibrium is well-defined with non-negative prices. Hence, together with $\kappa>0$, this case requires $\kappa \in\left(0, \frac{\mu}{3}\right)$.

Second suppose that period 2 is inactive with $\psi_{A}^{s}=\psi_{B}^{s}$ such that $X_{A}^{*}()+.X_{B}^{*}()=$.1 . Firm $i^{\prime}$ s profit function then equals $\pi_{i}()=.p_{i 1}\left[\widehat{Q}_{i 1}\left(p_{i 1}, p_{j 1}\right)\right]$ which can be rewritten as follows using eq. (7):

$$
\pi_{i}(.)=p_{i 1}\left[2 Q_{i 1}\left(p_{i 1}, p_{j 1}\right)\right]=2 p_{i 1}\left[\frac{1}{2}+\frac{p_{j 1}-p_{i 1}}{\mu}\right]
$$

However, to ensure $X_{A}^{*}()+.X_{B}^{*}()=$.1 , we know from Proposition 1 that eq. (16) must be maximised subject to $p_{i 1} \leq \kappa$. After solving and enforcing symmetry, this leads to a unique local maximum with $p_{1}^{*}=\min \left\{\kappa, \frac{\mu}{2}\right\}$ and $X^{*}=\frac{1}{2}$. There are no profitable local deviations because the associated second-order condition ensures local concavity, $\frac{\partial^{2} \pi_{i}(.)}{\partial p_{i 1}^{2}}=-\frac{2}{\mu}<0$. When $\kappa \in\left(0, \frac{\mu}{3}\right)$, we know from above that any symmetric equilibrium must have $X^{*}<0.5$. As this is inconsistent with $X_{A}^{*}()+.X_{B}^{*}()=$.1 , the current case must require $\kappa \geq \frac{\mu}{3}$.

\section{Proof of Proposition 4.}

The proof proceeds by initially deriving the equilibrium, before then comparing the level of stockpiling to that in the main model. First suppose that period 2 is active, with $X_{A}^{*}()+.X_{B}^{*}()<$.1 . In any symmetric 
equilibrium each firm has positive period 2 demand. Following the arguments in the text, $p_{i 2}^{*}$ is still given by Lemma 4 , and the expressions for stockpiling demand in Proposition $1, X_{i}^{*}($.$) and X_{j}^{*}($.$) , remain valid af-$ ter replacing $p_{i 1}$ and $p_{j 1}$ with the new effective costs of stockpiling a second unit, $D_{i 1}-p_{i 1}$ and $D_{j 1}-p_{j 1}$, respectively. Each firm $i$ must then choose $p_{i 1}$ and $D_{i 1}$ to maximise its profit function, which is now given by eq. (13) where $Q_{i 1}()=.\frac{1}{2}+\frac{p_{j 1}-p_{i 1}}{\mu}$ and $Q_{i 2}()=.\frac{1}{2}+\frac{p_{j 2}-p_{i 2}}{\mu}$. The associated first order conditions equal $\frac{\partial \pi_{i}(.)}{\partial p_{i 1}}=\frac{\kappa-4 p_{i 1}+2 D_{i 1}+2 p_{j 1}-D_{j 1}}{\mu}=0$ and $\frac{\partial \pi_{i}(.)}{\partial D_{i 1}}=\frac{4 p_{i 1}-2 p_{j 1}+2 D_{j 1}-4 D_{i 1}-2 \kappa+\mu}{2 \mu}=0$. After expanding, enforcing symmetry with $p_{i 1}=p_{j 1}=p_{1}^{*}$, and $D_{i 1}=D_{j 1}=D_{1}^{*}$, one obtains the unique values $p_{1}^{*}=\frac{\mu}{2}$ and $D_{1}^{*}=\mu-\kappa$. There are no profitable local deviations from these prices as the second order conditions ensure local concavity, $\partial^{2} \pi_{i}(.) / \partial^{2} p_{i 1}=-\frac{4}{\mu}<0$, and $\partial^{2} \pi_{i}(.) / \partial^{2} D_{i 1}=-\frac{2}{\mu}<0$. After substituting $D_{1}^{*}-p_{1}^{*} \equiv \frac{\mu}{2}-\kappa$ back into Lemma 4 and the revised version of Proposition 1 , one obtains $X^{*}=\frac{2 \kappa}{\mu}$ and $p_{2}^{*}=\frac{\mu}{2}-2 \kappa$ as claimed. For the period 2 market to be active as assumed, we then require $X^{*}=\frac{2 \kappa}{\mu}<\frac{1}{2}$. This leads to $\kappa>\mu / 4$, which also ensures that the equilibrium is well-defined with non-negative prices. Therefore, together with $\kappa>0$, this case requires $\kappa \in\left(0, \frac{\mu}{4}\right)$.

Second, suppose that period 2 is inactive such that $X_{A}^{*}()+.X_{B}^{*}()=$.1 . In this case, as all consumers stockpile, the firms are indifferent in period 1 between using single-unit prices or the bundle price, $D_{i 1} \equiv 2 p_{i 1}$. Suppose both firms only use single-unit prices. Then, the proof from the main model applies directly, with $p_{1}^{*}=\min \left\{\frac{\mu}{2}, \kappa\right\}$. Alternatively, suppose both firms use bundle prices. One can then verify that $D_{i 1}^{*} \equiv 2 p_{i 1}^{*}=$ $\min \{2 \kappa, \mu\}$. Either way, we know from above that any symmetric equilibrium under quantity discounts must have $X^{*}<0.5$ when $\mathcal{K} \in\left(0, \frac{\mu}{4}\right)$. As this is inconsistent with $X_{A}^{*}()+.X_{B}^{*}()=$.1 , the current case must require $\kappa \geq \frac{\mu}{4}$.

Finally, for any $x>0$, one can show that the level of stockpiling under quantity discounts is weakly higher than that in the main model because i) the level of stockpiling within the interior solution is relatively higher, $X^{*}=\frac{2 \kappa}{\mu}>\frac{3 \kappa}{2 \mu}$, and ii) the condition for the corner solution where all consumers stockpile is less strict, $\kappa \geq \frac{\mu}{4}<$ $\frac{\mu}{3}$.

\section{Proof of Proposition 5.}

Proceed by contradiction. Suppose no consumers stockpile in period 1. Building on the benchmark, the firms then receive a demand of $(1+\alpha) Q_{i t}\left(p_{i t}, p_{j t}\right)$ in each period. Using the first-order condition for a symmetric equilibrium, $p_{i t}^{*}=-\left[Q_{i t}\left(p_{i t}^{*}, p_{i t}^{*}\right) / Q_{i t}^{\prime}\left(p_{i t}^{*}, p_{i t}^{*}\right)\right]$, each firm therefore sets $p_{1}=p_{2}=p^{B}=\frac{\mu}{2}$. However, this cannot be an equilibrium because any consumer who can stockpile with $\kappa>0$ would then have an incentive to stockpile in period 1 as $p_{1}<p_{2}+\kappa$. Thus, in any symmetric equilibrium each firm must receive a positive level of stockpiling demand.

\section{Notes}

1 See, for example, Erdem, Imai, and Keane (2003) and Hendel and Nevo (2006a); Hendel and Nevo (2006a, b), Wang (2015) and Perrone (2017) and the references therein.

2 For instance, see Salop and Stiglitz (1982), Sobel (1984), Pesendorfer (2002), Hong, McAfee, and Nayyar (2002), Bell, Iyer, and Padmanabhan (2002), Anton and Das Varma (2005), Hosken and Reiffen (2007) and Gangwar, Kumar, and Rao (2013).

3 For evidence of the importance of visit costs for consumer decisions more generally, see Marshall and Pires (2018).

4 One can easily extend the model to allow consumers to have positive stockpiling costs, $s \geq 0$, as consistent with the costs of storing a product. The results then hinge on the level of net transaction costs, $(\kappa-s)$, rather than $\kappa$.

5 Although consistent with Guo and Villas-Boas (2007) and some related principles in mixed strategy equilibria, some readers may be uncomfortable with the feature that all consumers can be indifferent over stockpiling in equilibrium. However, one can construct a more complex model to break this indifference. For example, suppose that consumers with relatively stronger brand preferences also have relatively lower transaction costs, as consistent with richer consumers caring more about brands and finding it easier to visit stores. One can then generate an equivalent feature of this model where consumers with relatively stronger brand preferences have a strict incentive to stockpile and consumers with relatively weaker brand preferences have a strict incentive to not stockpile.

6 Although we do not explicitly model it, allowing market demand to be downward sloping would likely exaggerate these positive welfare results because the relative price decreases could also expand consumption.

7 Equivalently, the extra consumers can be thought of as facing transactions costs, $\kappa=-\infty$, such that they are never willing to stockpile.

\section{References}

Anton, J. J., and G. Das Varma. 2005. "Storability, Market Structure, and Demand-Shift Incentives." RAND Journal of Economics 36: 520-43. Armstrong, M. 2006. Recent Developments in the Economics of Price Discrimination. In: Blundell R., Newey W.K., and Persson T., editors. Advances in Economics and Econometrics: Theory and Applications, Volume II 97-141. Cambridge, UK: Cambridge University Press. Armstrong, M. 2017. “Ordered Consumer Search." Journal of the European Economic Association 15: 989-1024. 
Bell, D. R., G. Iyer, and V. Padmanabhan. 2002. “Price Competition under Stockpiling and Flexible Consumption.” Journal of Marketing Research 39: 292-303.

Boizot, C., J. M. Robin, and M. Visser. 2001. "The Demand for Food Products: An Analysis of Interpurchase Times and Purchased Quantities.” Economic Journal 111: 391-419.

Erdem, T., S. Imai, and M. P. Keane. 2003. “Brand and Quantity Choice Dynamics under Price Uncertainty." Quantitative Marketing and Economics 1: 5-64.

Gangwar, M., N. Kumar, and R. C. Rao. 2013. “Consumer Stockpiling and Competitive Promotional Strategies.” Marketing Science 33 (1): $94-$ 113.

Guo, L., and J. M. Villas-Boas. 2007. “Consumer Stockpiling and Price Competition in Differentiated Markets.” Journal of Economics and Management Strategy 16 (4): 827-58.

Hendel, I., and A. Nevo. 2006a. "Sales and Consumer Inventory." RAND Journal of Economics 37 (3): 543-62.

Hendel, I., and A. Nevo. 2006b. “Measuring the Implications of Sales and Consumer Inventory Behavior." Econometrica 74 (6): 1637-73.

Hendel, I., and A. Nevo. 2013. "Intertemporal Price Discrimination in Storable Goods Markets." American Economic Review 103 (7): $2722-51$.

Hong, P., R. P. McAfee, and A. Nayyar. 2002. “Equilibrium Price Dispersion with Consumer Inventories." Journal of Economic Theory 105 (2): 503-17.

Hosken, D., and D. A. Reiffen. 2007. "Pricing Behaviour of Multiproduct Retailers." B.E. Journal of Theoretical Economics 7 (1): 1-43.

Marshall, G., and T. Pires. 2018. "Measuring the Impact of Travel Costs on Grocery Shopping." Economic Journal 128: $2538-57$.

Perloff, J. M., and S. C. Salop. 1985. “Equilibrium with Product Differentiation." Review of Economic Studies 52 (1): 107-20.

Perrone, H. 2017. “Demand for Nondurable Goods: A Shortcut to Estimating Long-Run Price Elasticities." RAND Journal of Economics 48: 85673.

Pesendorfer, M. 2002. “Retail Sales: A Study of Pricing Behavior in Supermarkets.” Journal of Business 75 (1): 33-66.

Salop, S., and J. E. Stiglitz. 1982. "The Theory of Sales: A Simple Model of Equilibrium Price Dispersion with Identical Agents." American Economic Review 72 (5): 1121-30.

Sobel, J. 1984. "The Timing of Sales." Review of Economic Studies 51 (3): 353-68.

Wang, E. Y. 2015. "The Impact of Soda Taxes on Consumer Welfare: Implications of Storability and Taste Heterogeneity." RAND Journal of Economics 46 (2): 409-441.

Zhou, J. 2017. “Competitive bundling." Econometrica 85 (1): 145-72. 